trends, and hiring financial managers rather than academics-as is the case currently-to steer financial decisions.

DOI: http://dx.doi.org/10.60I7/ihe.2019.97.10789

\section{Exploring Equity in Higher Education Systems: Reflec- tions from Argentina and Chile}

\section{Ana García de Fanelli}

Ana García de Fanelli is a senior research scholar of the National Scientific and Technical Research Council (CONICET) at the Center for the Study of State and Society (CEDES) in Buenos Aires, Argentina. E-mail:anafan@cedes.org.

P ublic debates on equity in higher education usually focus on the impact of admissions and funding policies on a system as a whole. First, it is assumed that the more selective admission criteria and procedures are, the fewer the opportunities will be for lower-income students to access higher education. Second, it is assumed that the cost sharing of undergraduate studies through tuition fees can reduce the chance of less privileged social strata pursuing higher education. Although both premises are true, two additional factors can significantly affect equity in higher education: the capacity of the secondary school and undergraduate levels to retain and provide high-quality education to lower-income and culturally disadvantaged students; and institutional differentiation, which results in vertical stratification in terms of status, with lower-income students attending low-quality institutions.

\section{Access and Funding in Argentina and Chile}

We can illustrate the complexities of the interaction between policies and equity outcomes with two cases from Latin America, which exhibit polarized access and funding policies. Argentina has a nonselective admissions policy for most undergraduate programs (e.g., no entrance exam or maximum number of vacancies) and these same programs are tuition-free in the public sector, which, consequently, has the highest proportion of the enrollment (75 percent of total enrollment in 20I5). The Chilean system, in contrast, is based on selective admissions policies and significant tuition fees in the context of a considerably privatized higher education market structure (in 20I7, 84 percent of enrollment was in the private sector). In principle, we should expect better equity outcomes in Argentina than in Chile.

However, the evolution of the participation rates of the lowest income quintile in these two countries does not reflect this assumption. Chile has rapidly improved access to higher education for students belonging to the lowest strata, surpassing Argentina's net enrollment rate (NER). According to data based on National Household Surveys compiled by the Socio-Economic Database for Latin America and the Caribbean (SEDLAC) in 20I5, the lowest income quintile's NER was 29 percent in Chile and I9 percent in Argentina. Ten years earlier, these same rates were 13 and 16 percent, respectively. Moreover, in 20I5, the ratio between the top quintile's and the bottom quintile's participation in higher education was 2.2 in Chile and 2.8 in Argentina.

These participation indicators do not necessarily imply that Chilean higher education is in all aspects more equitable than that of Argentina, but they call attention to the complexity of the equity challenge in the context of massification and differentiation of higher education. In addition, both systems show marked inequalities. In order to understand better the factors that impinge on equality, we need to examine the two issues mentioned above: the chances that lower-income students have of finishing secondary school and persisting in their undergraduate studies, and the types of institutions that they can attend.

\section{Secondary SCHOOl Completion and Undergraduate DROPOUT RATES}

The graduation rate at the secondary school level clearly explains why Argentina lags behind Chile in terms of higher education NER of lower-income students. According to OECD data, the 2015 upper secondary school graduation rate in Chile was 90 percent, while it was 6r percent in Argentina. In terms of quality, PISA results show that Chile has achieved better marks and improvements over time than Argentina, although these are still below the OECD average. Therefore, in the context of low graduation rates and poor quality achievements at the secondary school level, Argentina's open access and tuition free policies cannot foster inclusion in undergraduate higher education.

In both countries, the poor academic results of lowerincome students hinder their progress in undergraduate programs and result in higher dropout rates during the first year of study. According to estimates of the Chilean Higher Education Information Service (SIES), the first-year dropout rate for the 2008-20I2 cohorts were around 30 percent. The data showed greater dropout rates among lowerincome students with less educated parents and students who had graduated from subsidized private or municipal/ 
public schools. In Argentina, comparable data are not available, but based on the Household National Survey, we calculated the global dropout rates by socioeconomic status among young people (I8-30 years old). The data showed that lower-income students had a higher global dropout rate ( 55 percent) than those in the middle-income group (40 percent) or in the high-income group (2I percent).

\section{Hierarchical Differentiation}

During the past decade, both in Argentina and Chile, the most dynamic institutions in terms of undergraduate enrollment expansion have not been top-tier institutions but, rather, nonuniversity public or private tertiary institutions and private universities.

In Argentina, although most of the undergraduate enrollment is at public universities, this sector's participation in the total enrollment has decreased by almost io percent in one decade (from 63 to 54 percent of the total undergraduate enrollment between 2005 and 2015). The highest in-

\section{Chile has rapidly improved access to higher education for students belonging to the lowest strata, surpassing Argen- tina's net enrollment rate (NER).}

crease was registered in the public and, to a lesser extent, in the private, nonuniversity tertiary sector that trains primary and secondary school level teachers and offers short vocational and technical programs. In addition, some nonselective, teaching-oriented private universities expanded their enrollment faster than elite, private institutions or public universities.

In Chile, 6I percent of the $20 \mathrm{I7}$ undergraduate enrollment was concentrated in mostly nonselective professional institutes and in independent private universities (those universities that do not belong to the selective and higherquality public and private Council of Rectors of Chilean Universities sector). At professional institutes, vocational degrees showed the highest growth rates between 2008 and 2017 . Since 2006 , and especially after the student movement of 20II, student-funding policies have promoted access to these sectors through the expansion of student loan and grant programs also covering technical education. The new gratuidad (tuition-free) law, enacted in 2016 and targeting low- and middle-income students, may also help expand the number of low-income students who have access to the least selective programs and institutions. This financial aid measure does not require students to achieve a minimum score on the national college admissions test (PSU), which is still a condition for grants and loans programs.

In sum, massification in both countries has improved the access of new generations of lower-income secondary school graduates to less selective and lower-quality programs in the public and private sectors. The vertical stratification among higher education institutions has increased as a result of a lack of communication channels and mobility pathways between them.

\section{CONCLUSION}

Given the complexities of massification and institutional differentiation in higher education, it is not possible to analyze the equity of a given system by focusing only on general policies regulating access and state or private funding mechanisms. When focusing on secondary school and undergraduate dropout rates and on the programs and institutions that lower-income students attend, striking inequalities may appear. To conduct this type of analysis, it is necessary to produce more and better indicators accounting for quantitative and qualitative transformations of the student body, as well as for the institutional stratification occurring as a result of increasingly massified and heterogeneous secondary school and higher education sectorsdevelopments that are occurring throughout Latin America. DOI: http://dx.doi.org/10.60I7/ihe.20I9.97.I0950n

\section{Development of the Credit System in Kazakhstan}

\section{ARAy Ilyassova-SChOEN FELD}

Aray Ilyassova-Schoenfeld is a postdoctoral scholar at the Graduate School of Public Policy, Nazarbayev University, Kazakhstan. E-mail: ailyassova@nu.edu.kz.

Ater the collapse of the Soviet Union in I99I, it became Aessential for Kazakhstan to increase the quality and competitiveness of its higher education. Its aim was to become a part of the European or American systems, and/ or an OECD member, in order to enhance the recognition of its researchers and faculty, and of their work. It took a long journey before Kazakhstan achieved its goals. All educational reforms in Kazakhstan, including changes in the structure or content of education, as well as credit system 